\title{
Constitutive model describing the hydro-mechanical behaviors of compacted bentonite clay based on the crystal surface phenomena
}

\author{
Hiroyuki Kyokawa ${ }^{1 *}$ \\ ${ }^{1}$ University of Tokyo, Department of Civil Engineering, 113-8656 Tokyo, Japan
}

\begin{abstract}
A constitutive model for unsaturated expansive soil based on the crystal surface phenomena is proposed. The behavior of the proposed model is described as a double structure, with the soil skeleton and the interlaminar behaviors. The soil skeleton behavior is modeled by the Cam clay type model based on the Bishop's effective stress, which can consider the degree of saturation-induced hardening and inelastic behavior in the over-consolidated region and is capable of describing hydraulic collapse. On the other hand, the interlaminar behavior is give as a result of the interlaminar equilibrium of clay minerals. The diffusion double layer repulsive force in the interlaminar equilibrium varies with the degree of saturation, and it mainly causes the hydraulic swelling of expansive soil. The performance of the model is validated through the simulations of the suction-controlled oedometer tests on the heavily compacted bentonite.
\end{abstract}

\section{Introduction}

Expansive soils (bentonite) are intended as sealing and/or buffer materials surrounding radioactive waste in waste disposal facilities. Bentonite is studied in this capacity because of its swelling characteristics, self-healing properties, low permeability, and radionuclide absorptivity. Considering the environment around disposal facilities during the in-service periods, i.e., fluid flow and heat transport, the thermo-hydro-mechanical (THM) behavior of various bentonites has been intensively examined. Most of these investigations have considered heavily compacted bentonite or bentonite mixtures under unsaturated conditions.

Expansive soils are mainly composed of smectitegroup clay minerals, such as montmorillonite, which are formed by the negatively charged clay mineral crystal (aluminum silicate) in an electrolyte solution. Hydrated exchangeable cations are attracted to such negatively charged crystals to maintain electrical neutrality, resulting in an expansive behavior. The electrochemical phenomena on the mineral surface explain a certain type of swelling behavior and provide the actual mechanism of expansion. Kyokawa et al. (2020) [1] proposed a doublestructure model that represents the macroscopic behavior of the saturated expansive soils as a combination of the soil skeleton behavior and the interlaminar behavior of clay mineral crystals based on the electrical/chemical phenomena on clay crystal surfaces. The model could simulate the osmotic swelling/consolidation behavior and the influence of the pore fluid composition on such osmotic phenomena only in its saturated state.

In this study, the model was extended to one considering the unsaturated condition. The soil skeleton behavior should be given by the model describing the typical behaviors of unsaturated soil; for example, the degree of saturation-induced hardening and the hydraulic collapse. Suction and the degree of saturation would also affect the interlaminar behavior of clay mineral crystals in the unsaturated state. It is assumed that the contribution of the diffusion double layer repulsive force, which fully occurs when there is a continuity of water between the interlaminar space and the soil skeleton, to the interlaminar phenomena changes with the degree of saturation. The performance of the proposed model is validated through simulations of the series of the suctioncontrolled oedometer tests on the heavily compacted FEBEX bentonite [2].

\section{Constitutive modeling of unsaturated expansive soil based on electrical/chemical phenomena on clay crystal surface}

\subsection{Double-structure framework of unsaturated expansive soil}

Figure 1 shows a schematic of an unsaturated expansive soil composed of expansive clay minerals (multilayered crystals) and non-expansive soil particles. $V^{\mathrm{s}}$ is the total volume of the soil particles, $V^{\mathrm{sE}}$ is the volume of the expansive soil minerals, $V^{\mathrm{sNE}}$ is the volume of the nonexpansive soil, $V^{\mathrm{v}}$ is the volume of the void, $V^{\mathrm{il}}$ is the volume of the interlaminar space between crystals corresponding to the micro-structure, and $V^{\text {ss }}$ is the

\footnotetext{
* Corresponding author: kyokawa@civil.t.u-tokyo.ac.jp
} 


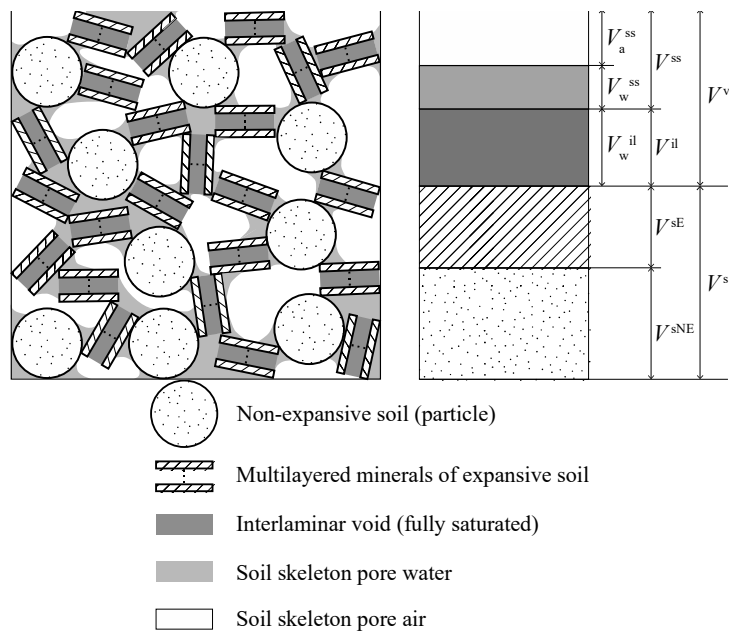

Fig. 1. Schematic figure of unsaturated expansive soil

volume of soil skeleton voids corresponding to the macrostructure. A double structure framework, namely soil skeleton and interlayer of clay crystals, is assumed for expansive soils. The void ratio variables are given by

$$
\left\{\begin{array}{c}
e=V^{\mathrm{V}} / V^{s} \\
e^{\mathrm{il}}=V^{\mathrm{il}} / V^{\mathrm{s}} \\
e^{\mathrm{ss}}=V^{\mathrm{ss}} / V^{\mathrm{s}}
\end{array}\right.
$$

The volume change in expansive soil can be expressed as follows:

$$
\varepsilon_{\mathrm{v}}=-\frac{V-V_{0}}{V_{0}}=-\frac{\Delta V^{\mathrm{ss}}+\Delta V^{\mathrm{il}}}{V_{0}^{\mathrm{s}}+V_{0}^{\mathrm{sS}}+V_{0}^{\mathrm{il}}}
$$

$V_{0}$ is the initial volume of soil. Kyokawa et al. (2020) [1] proposed volume changes in soil skeleton and interlaminar space, and provided the total strain of expansive soils as follows.

$$
\begin{gathered}
\Delta V^{\text {ss }}=-\left(V_{0}^{\mathrm{s}}+V_{0}^{\mathrm{ss}}+V_{0}^{\mathrm{il}}\right) \varepsilon_{\mathrm{V}}^{\mathrm{ss}} \\
\frac{\Delta V^{\mathrm{il}}}{V_{0}^{\mathrm{il}}}=\frac{d-d_{0}}{d_{0}} \\
\varepsilon_{i j}=\varepsilon_{i j}^{\mathrm{ss}}-\frac{1}{3} \theta^{*} \frac{d-d_{0}}{d_{0}} \delta_{i j} \\
\text { where } \theta^{*}=\frac{e_{0}^{\mathrm{il}}}{1+e_{0}^{\mathrm{ss}}+e_{0}^{\mathrm{il}}}
\end{gathered}
$$

$d$ is the representative distance of the interlaminar space and $d_{0}$ is its initial value. $\varepsilon_{i j}^{\text {ss }}$ is the soil skeleton strain and $\varepsilon_{\mathrm{V}}{ }^{\mathrm{ss}}$ is its volumetric component. Note that positive strain implies contraction and the smalldeformation theory is assumed in the proposed model.

For unsaturated state, definition of degree of saturation is necessary. In Figure $1, V_{\mathrm{a}}^{\mathrm{ss}}$ and $V_{\mathrm{w}}^{\mathrm{ss}}$ are the volumes of air and water in the volume of soil skeleton void respectively, and $V_{\mathrm{w}}^{\mathrm{il}}$ is the volume of water in the interlaminar space. The interlaminar space is assumed to be always fully saturated in this study [3], thus $V_{\mathrm{w}}{ }^{\text {il }}$ is equal to $V^{\text {il }}$. Thus, the degree of saturation is given as

$$
\begin{gathered}
S_{\mathrm{r}}=\frac{V_{\mathrm{w}}^{\mathrm{il}}+V_{\mathrm{w}}^{\mathrm{ss}}}{V^{\mathrm{il}}+V^{\mathrm{ss}}}=\frac{V^{\mathrm{il}}+S_{\mathrm{r}}^{\mathrm{ss}} V^{s s}}{V^{\mathrm{il}}+V^{s \mathrm{~s}}}=\frac{e^{\mathrm{il}} / e^{\mathrm{ss}}+S_{\mathrm{r}}^{\mathrm{ss}}}{e^{\mathrm{il}} / e^{\mathrm{ss}}+1} \\
S_{\mathrm{r}}^{\mathrm{ss}}=\frac{V_{\mathrm{w}}^{\mathrm{ss}}}{V^{s \mathrm{~s}}}
\end{gathered}
$$

Here, $S_{\mathrm{r}}^{\mathrm{ss}}$ is the degree of saturation of soil skeleton. The interlaminar distance, the soil skeleton strain and the relationship between suction and degree of saturation, i.e., soil water characteristic curve, are modeled following sections.

\subsection{The soil skeleton behavior - Macro-structure behavior}

The soil skeleton behavior is due to arrangement and orientation of the clay crystals, and it directly relates to mechanical deformation and strength characteristics. Expansive soil exhibits stiffer behavior and higher strength with increase in suction [4]. Additionally, in spite of expansive soil, the collapse behavior with decreasing in suction, namely wetting, has been observed [5]. In other words, the mechanical behavior of unsaturated expansive soil is basically similar to that of non-expansive soil. Therefore, the soil skeleton behavior of unsaturated expansive soil is modeled based on the model proposed by Kikumoto et al. (2010) [6], which is the Cam clay type elastoplastic model using Bishop's effective stress.

In the proposed model, the effective stress parameter $\chi$ in Bishop's effective stress is given as the degree of saturation of soil skeleton:

$$
\begin{aligned}
\sigma^{\prime \prime}{ }_{i j} & =\left(\sigma_{i j}-u^{a} \delta_{i j}\right)+\chi\left(u^{a}-u^{a}\right) \delta_{i j} \\
& =\sigma_{i j}^{\text {net }}+\chi s=\sigma_{i j}^{\text {net }}+S_{\mathrm{r}}^{\text {ss }} s
\end{aligned}
$$

This is same as the effective degree of saturation by Alonso et al. (2010) [7] and Mašín (2013) [3]. The surface tension acting on soil skeleton contributes to the effective stress governing mechanical characteristics of geomaterials. The consideration of osmotic suction in the effective stress for (unsaturated) expansive soils has been often discussed [8]. Such osmotic suction is considered as a repulsion force caused by the crystal surface phenomena in the proposed model which is explained later.

The soil skeleton strain is the sum of elastic and plastic components.

$$
\varepsilon_{i j}^{\mathrm{ss}}=\varepsilon_{i j}^{\mathrm{ess}}+\varepsilon_{i j}^{\mathrm{pss}}
$$

The elastic soil skeleton strain is given by Hooke's law.

$$
\begin{aligned}
& \delta \varepsilon_{i j}^{\text {ss e }}=\frac{1+v_{\mathrm{e}}}{E} \delta \sigma^{\prime \prime}{ }_{i j}-\frac{v_{\mathrm{e}}}{E} \delta \sigma^{\prime \prime}{ }_{k k} \delta_{i j} \\
& \text { where } E=\frac{3\left(1-2 v_{\mathrm{e}}\right)\left(1+e_{0}\right)}{\kappa} p^{\prime \prime}
\end{aligned}
$$

Using the effective stress (Eq. (8)), the yield function is defined as follows: 


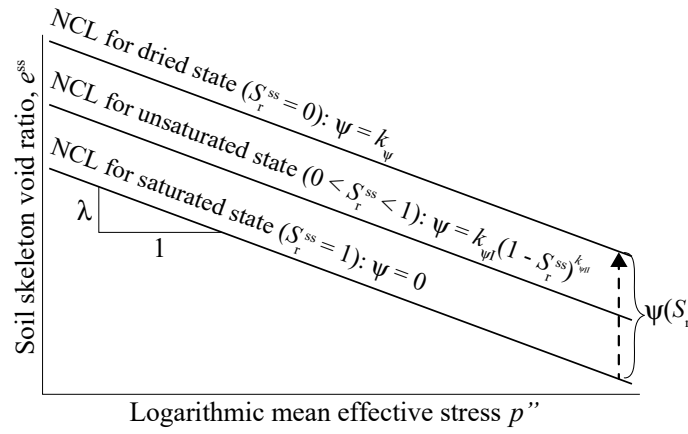

Fig. 2. Schematic of the normally consolidated line of the soil skeleton and the state parameter $\psi$

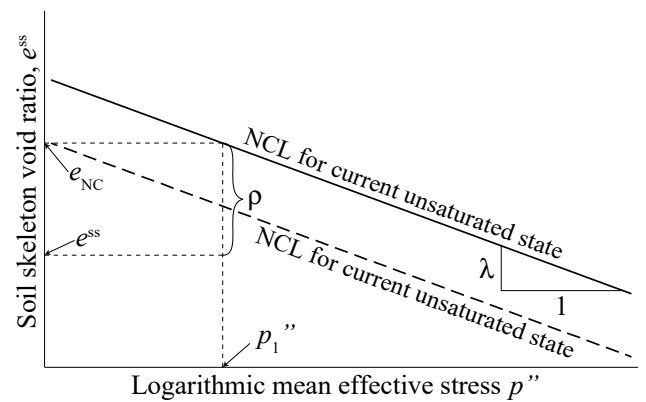

Fig. 3. Schematic of the density state parameter $\rho$

$$
\begin{aligned}
& f=\ln \frac{p^{\prime \prime}}{p_{0}^{\prime \prime}}+\ln \left(\frac{M^{2}+\left(q / p^{\prime \prime}\right)^{2}}{M^{2}}\right)-\frac{1}{\mathrm{C}_{\mathrm{p}}} \varepsilon_{\mathrm{v}}^{\mathrm{p} s \mathrm{~s}} \\
& -\frac{1}{\mathrm{C}_{\mathrm{p}}}\left(\frac{\psi-\psi_{0}}{1+e_{0}}\right)+\frac{1}{\mathrm{C}_{\mathrm{p}}}\left(\frac{\rho-\rho_{0}}{1+e_{0}}\right)=0
\end{aligned}
$$

$\psi$ represents the vertical movement of normally consolidated line according to the unsaturated state, and $\psi_{0}$ is its initial value (Figure 2). The development of $\psi$ is assumed as a non-negative monotonic increasing function of the degree of saturation of soil skeleton in this study.

$$
\psi=k_{\mathrm{I}}\left(1-S_{\mathrm{r}}^{\mathrm{sS}}\right)^{k_{\mathrm{II}}}
$$

$k_{\mathrm{I}}$ and $k_{\mathrm{II}}$ are material parameters. When $S_{\mathrm{r}}^{\mathrm{ss}}$ is 0.0 (fully dried state), $\psi$ is equal to $k_{\mathrm{I}}$. An increase in the degree of saturation of soil skeleton during the wetting process, $\psi$ subsequently decreases, the normally consolidated line moves downward, and this process causes the hydraulic collapse of soil skeleton. On the other hand, $\rho$ is the distance between the current void ratio and the corresponding void ratio on the current normally consolidated line (Nakai and Hinokio (2004)) [9] (see Figure 3), which moves upward/downward, according to the degree of saturation of soil skeleton (Eq. (7)). $\rho$ is the state parameter representing the magnitude of overconsolidation, and elastoplastic behavior is exhibited in the over-consolidated state by the following evolution rule of $\rho$.

$$
\delta\left(\frac{\rho}{1+e_{0}}\right)=-a \rho|\rho|\left\|\delta \varepsilon_{i j}^{\mathrm{pss}}\right\|
$$

$\rho$ monotonically decreases with the plastic soil skeleton strain. This means that the influence of over-consolidation

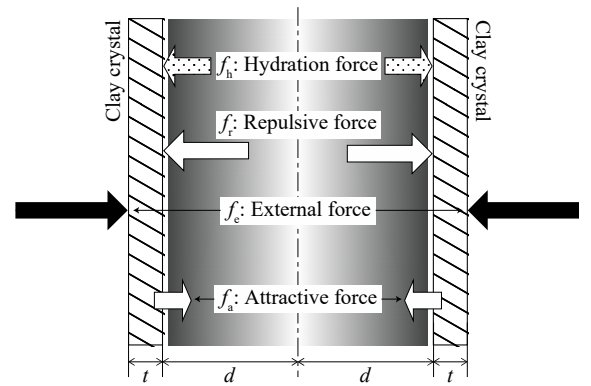

Fig. 4. Interlaminar equilibrium (forces acting on interlayer)

dissipates with plastic deformation. Assuming the flow rule (Eq. (14)), considering the consistency condition $(\delta f$ $=0$ ) with Eqs. (11)-(13) and Eq. (25), and finally obtaining the plastic coefficient $\Lambda$ in Eq. (14), the plastic soil skeleton strain can be calculated.

$$
\delta \varepsilon_{i j}^{\text {ss p }}=\Lambda \frac{\partial f}{\partial \sigma^{\prime \prime}}
$$

\subsection{The interlaminar behavior - Micro-structure behavior}

Kyokawa et al. (2020) [1] derived the interlaminar distance $d$ of saturated expansive soils from the interlaminar equilibrium based on the study of surface chemistry. This interlaminar equilibrium is extended for unsaturated expansive soils as well as the soil skeleton strain in this study. Figure 4 shows a schematic of the interlaminar equilibrium, in which the attractive and repulsive forces act on adjacent crystals of a clay mineral and sustain the equilibrium. This equilibrium is formulated as

$$
F^{*}\left(d, c, \sigma^{\prime \prime}{ }_{i j}, S_{\mathrm{r}}^{\mathrm{ss}}\right)=f_{\mathrm{a}}-f_{\mathrm{r}}-f_{\mathrm{h}}+f_{\mathrm{e}}=0
$$

where $f_{\mathrm{a}}$ is the van der Waals attractive force, $f_{\mathrm{r}}$ is the double layer repulsive force, $f_{\mathrm{h}}$ is the hydraulic repulsive force, and $f_{\mathrm{e}}$ is the external force. Again, $d$ is the representative distance of interlaminar space, $c$ is the concentration of the solution in the soil skeleton void, $\sigma_{i j}^{\prime \prime}$ is Bishop's effective stress (Eq. (8)), and $S_{\mathrm{r}}^{\text {ss }}$ is the degree of saturation of soil skeleton.

The surface of crystals in expansive soil minerals is negatively charged, and thus attracts exchangeable cations in the pore fluid. This attraction establishes the diffusion double layer around crystals and yields a repulsive force when adjacent layers overlap. It is noted that this repulsion is derived from the osmotic pressure, which is due to the concentration difference between the overlapping space of the double layers of adjacent objects; that is, the interlaminar space, and the region outside that space (the soil skeleton void). In other words, the osmotic pressure would be zero if there is no continuity of water between the interlaminar space and the soil skeleton, namely fully dried condition. Additionally, some previous studies have reported that the osmotic swelling due to diffusion double layer becomes dominant with an increase in the relative humidity and/or suction [10]. Thus, relating 
to the degree of saturation of soil skeleton, the repulsive force due to diffusion double layer of unsaturated expansive soil is given as follows:

$$
\begin{gathered}
f_{\mathrm{r}}=S_{\mathrm{r}}^{\mathrm{ss}} f_{\mathrm{r}}^{\prime} \\
f_{\mathrm{r}}^{\prime}=\frac{1}{C E C} \sum_{\substack{i=\mathrm{Na}^{+}, \mathrm{Ca}^{2+}, \ldots}} E X C_{i} \cdot f_{\mathrm{r} i}^{\prime}\left(c_{i}, d\right)[\mathrm{kPa}] \\
f_{\mathrm{r} i}^{\prime}\left(c_{i}, d\right)=2 c_{i} N_{\mathrm{A}} k T\left\{\cosh \left(u_{i}\right)-1\right\} \times 10^{-3}[\mathrm{kPa}] \\
u_{i}=8 \tanh ^{-1}\left\{\exp \left(-\omega_{i} d\right) \cdot \tanh \left(z_{i} / 4\right)\right\} \\
\omega_{i}=\sqrt{\left(2 c_{i} N_{\mathrm{A}} v^{2} e^{\prime 2}\right) /(\epsilon k T)}\left[\mathrm{m}^{-1}\right] \\
z_{i}=2 \sinh ^{-1}\left(96.5 E X C_{i} / S\left(8 \epsilon c_{i} N_{\mathrm{A}} k T\right)^{-1 / 2}\right)
\end{gathered}
$$

$f_{\mathrm{r}}{ }^{\prime}$ is the repulsive force proposed by referring to Komine and Ogata (1996) [11]. Note that the simulations (shown in a later section) consider a single-ion $\left(\mathrm{Ca}^{2+}\right)$ solution in this study.

The van der Waals attractive force between two parallel layers [12] is given as

$$
\begin{aligned}
& f_{\mathrm{a}}(d)= \\
& \frac{A_{\mathrm{h}}}{24 \pi}\left\{\frac{1}{d^{3}}+\frac{1}{(d+t)^{3}}-\frac{2}{(d+t / 2)^{3}}\right\} \times 10^{-3}[\mathrm{kPa}]
\end{aligned}
$$

The hydraulic repulsive force is considered, particularly for compacted bentonite, which has a very small space between mineral crystals. This repulsive force monotonically decreases with distance and is empirically given by the following equation [13]:

$$
f_{\mathrm{h}}(d)=\left(W_{0} / \chi_{0}\right) \exp \left(-d / \chi_{0}\right) \times 10^{3} \quad[\mathrm{kPa}]
$$

The external force $f_{\mathrm{e}}$ consists of the effective stress, which is defined by Eq. (12) in the proposed model. For simplicity, the mean effective stress $p^{\prime \prime}$ is used:

$$
f_{\mathrm{e}}\left(\sigma^{\prime \prime}{ }_{i j}\right)=p^{\prime \prime}[\mathrm{kPa}]
$$

Solving the interlaminar equilibrium Eq. (15) with Eqs. (16)-(24), the interlaminar distance $d$ can be uniquely determined.

\subsection{Soil water characteristic curve (SWCC) - Micro and macro water retention characteristics}

For the degree of saturation of soil skeleton $S_{\mathrm{r}}^{\mathrm{ss}}$, a classical SWCC model provides a monotonic, decreasing, single-valued function of suction ranging from 0 to 1 . A function proposed by van Genuchten (1980) [14] is

\begin{tabular}{|c|c|c|c|}
\hline$\lambda, \kappa$ & $\begin{array}{l}\text { Compression and swelling } \\
\text { indexes }\end{array}$ & - & $\begin{array}{l}0.090 \\
0.040\end{array}$ \\
\hline$M$ & Critical stress ratio & - & 0.30 \\
\hline$v_{\mathrm{e}}$ & Poisson's ratio & - & 0.43 \\
\hline$e_{\mathrm{NC}}$ & $\begin{array}{l}\text { Reference void ratio on } \\
\text { NCL at } p=\mathrm{Pa}\end{array}$ & - & 0.75 \\
\hline $\mathrm{Pa}$ & $\begin{array}{l}\text { Reference confining } \\
\text { pressure }\end{array}$ & $\mathrm{kPa}$ & 100 \\
\hline$a$ & Effect of density & - & 10 \\
\hline$k_{\mathrm{I}}, k_{\mathrm{II}}$ & Effect of unsaturated state & - & $\begin{array}{l}0.44 \\
0.50\end{array}$ \\
\hline \multicolumn{4}{|c|}{ Parameters of water retention curve (van Genuchten model) } \\
\hline$\alpha$ & VG model parameter & $1 / \mathrm{kPa}$ & $6.0 \mathrm{E}-5$ \\
\hline$m, n$ & VG model parameter & - & $\begin{array}{l}0.4 \\
1.667 \\
\end{array}$ \\
\hline \multicolumn{4}{|c|}{ Material specification } \\
\hline$e_{0}^{\mathrm{sS}}$ & Initial soil skeleton ratio & - & $e_{0}-e_{0}^{\mathrm{il}}$ \\
\hline$e_{0}^{\text {il }}$ & $\begin{array}{l}\text { Initial interlaminar void } \\
\text { ratio }\end{array}$ & - & 0.36 \\
\hline
\end{tabular}
selected in this study for simplicity.

$$
S_{\mathrm{r}}^{\mathrm{ss}}=\left(1+(\alpha s)^{n}\right)^{-m}
$$

Although the hydraulic hysteresis of soil water characteristic curve in expansive soils [15] has been confirmed, the consideration of hysteresis will be considered in future studies.
Table. 1. Constitutive parameters (FEBEX $\left.\rho_{\mathrm{d}}=1.65\right)$

Parameters of constitutive model (soil skeleton behavior)

Physical constants

\begin{tabular}{clll}
\hline$A_{\mathrm{h}}$ & Hamaker constant & $\mathrm{J}$ & $2.20 \mathrm{E}-20$ \\
\hline$k$ & Boltzmann constant & $\mathrm{J} / \mathrm{K}$ & $1.38 \mathrm{E}-23$ \\
\hline$e^{\prime}$ & Electronic charge & $\mathrm{C}$ & $1.61 \mathrm{E}-19$ \\
\hline
\end{tabular}

\begin{tabular}{clll}
\multicolumn{2}{l}{ Clay mineral specification } & & \\
\hline$t$ & Thickness of crystal & $\mathrm{m}$ & $9.60 \mathrm{E}-10$ \\
\hline$S$ & $\begin{array}{l}\text { Specific surface area of } \\
\text { crystal }\end{array}$ & $\mathrm{m}^{2} / \mathrm{g}$ & 725 \\
\hline $\begin{array}{c}C E C, \\
E X C_{\mathrm{Ca}^{2+}}\end{array}$ & $\begin{array}{l}\text { Cation exchange capacity } \\
\text { and that of } \mathrm{Ca}^{2+}\end{array}$ & $\mathrm{mEq} / \mathrm{g}$ & $1.0,1.0$ \\
\hline$v$ & $\begin{array}{l}\text { Valence of exchangeable } \\
\text { cation }\end{array}$ & - & 2 \\
\hline$W_{0}$ & $\begin{array}{l}\text { Parameter for the } \\
\text { hydration force }\end{array}$ & $\mathrm{MJ} / \mathrm{m}^{2}$ & $1.00 \mathrm{E}-04$ \\
\hline$\chi_{0}$ & $\begin{array}{l}\text { Parameter for the } \\
\text { hydration force }\end{array}$ & $\mathrm{m}$ & $1.00 \mathrm{E}-10$
\end{tabular}

\begin{tabular}{clll}
\hline \multicolumn{2}{l}{ Pore water specification } \\
\hline$T$ & Absolute temperature & $\mathrm{K}$ & 293.15 \\
\hline$\varepsilon$ & $\begin{array}{l}\text { Electronic permittivity of } \\
\text { water }\end{array}$ & $\mathrm{C}^{2} /(\mathrm{J} \cdot \mathrm{m})$ & $7.08 \mathrm{E}-10$ \\
\hline
\end{tabular}

\section{Simulation results}

\subsection{Constitutive parameters}

A series of suction-controlled oedometer tests on heavily compacted FEBEX bentonite (Lloret et al., 2003) [2] were simulated by the proposed model. The constitutive parameters are listed in Table 1. The parameters of soil skeleton deformation, initial soil skeleton and interlaminar void ratios are determined mainly by fitting the observed result of S1 (described in later section), which includes a wide range of suction changes from 520 $\mathrm{MPa}$ to $0 \mathrm{MPa}$ and a vertical stress change from $0.1 \mathrm{MPa}$ 


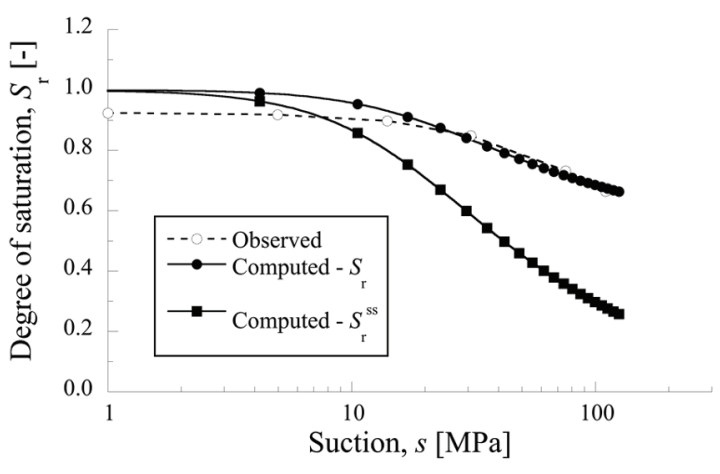

Fig. 5. Soil water characteristic curve (FEBEX $\left.\rho_{\mathrm{d}}=1.65\right)$

to $5.0 \mathrm{MPa}$ under zero suction condition, namely almost saturated condition in which the influence of unsaturated state is negligible. Moreover, the critical stress ratio $M$ is evaluated from the literature [16]. The specific surface area of crystal $S$ and cation exchange capacity are provided in the literature [2]. Other parameters of bentonite and pore water specifications were set by referring to previous work (Kyokawa, 2020). Only calcium ion: $\mathrm{Ca}^{2+}$ is considered in this study, as calcium ion has the highest composition ratio (38\%) among other cations $\left(\mathrm{Mg}^{2+}: 28 \% ; \mathrm{Na}^{+}: 23 \% ; \mathrm{K}^{+}: 2 \%\right)$.

The parameters for SWCC, modeled by van Genuchten model, were given by fitting the observed of SWCC under constant volume condition (or in other words, swelling pressure test, where $\rho_{\mathrm{d}}=1.65 \mathrm{Mg} / \mathrm{m}^{3}$ ). Figure 5 shows the observed and computed results, and it can be observed that the computed total degree of saturation is in good agreement with the observed one. As given in Eq. (6), the total degree of saturation is calculated as a result of the combination of the soil skeleton and interlaminar void ratios, which strongly depend on the mechanical behavior, and the degree of saturation of soil skeleton. Thus, the computed total degree of saturation and the degree of saturation of soil skeleton are shown simultaneously in Figure 5.

\subsection{Simulation results of oedometer tests controlling suction and vertical stress}

The initial conditions and the stress paths of the tests are shown in Table 2 (Lloret et al., 2003) [2]. In the simulation, suction / vertical stress changes under constant vertical stress / suction with K0 condition were computed as well as the experiments. The concentration of $\mathrm{Ca}^{2+}$ in the soil skeleton void was assumed to be $1.0 \mathrm{E}$ -
$3 \mathrm{~mol} / \mathrm{L}$ (representing the distilled water), and it is constant in all cases of the simulations.

Figures 6 and 7 show the observed results and the corresponding computed results: (a) the relationship between vertical stress and void ratio; b) the relationship between suction and void ratio. It can be observed from the figures that the proposed model can properly capture the observed results. The proposed model, which considers the influences of unsaturated state and density and/or confining pressure on the soil skeleton behavior, can properly simulate the mechanical consolidation behavior under various void ratios and suctions. The large swelling behavior with decrease in suction / increase in the degree of saturation, i.e., wetting process, can be captured by the proposed model. Furthermore, from the comparison between $\mathrm{S} 1$ and $\mathrm{S} 5$, the stress level dependency of swelling, namely the larger swelling occurs under the lower confining stress, can be properly considered. As suction decreases and the degree of saturation (of the soil skeleton) increases, the effective stress decreases (Eq. (8)) while the diffusion double layer repulsive force increases (Eq. (16)). This contributes to the interlaminar swelling governed by the interlaminar equilibrium (Eq. (15)). Additionally, it should be noted that the mechanical swelling due to the decrease in effective stress, that is, unloading, and the hydraulic collapse simultaneously occurs in the soil skeleton during wetting process. Therefore, as a result of a balance observed between interlaminar swelling, mechanical swelling, and hydraulic collapse in the soil skeleton, a volume change in unsaturated expansive soils due to wetting occurs in the proposed model.

\section{Conclusion}

In this study, the constitutive model for saturated expansive soils (Kyokawa et al. 2020) [1] was extended to one considering the unsaturated state. The proposed model is based on double structure framework, namely the soil skeleton and the interlaminar behaviors, and not only the void ratio variables but also the degree of saturation variables were defined for the unsaturated double structure. For the soil skeleton behavior, the Cam clay type elastoplastic model, considering the influences of density (and/or confining pressure) and unsaturated state was used. It was formulated by Bishop's effective stress, where the effective stress parameter $\chi$ is the degree of saturation of soil skeleton. In the interlaminar equilibrium, the contribution of diffusion double layer

Table. 2. Initial conditions and stress paths

\begin{tabular}{|c|c|c|c|c|c|c|c|c|c|c|c|}
\hline \multirow{3}{*}{ Test } & \multicolumn{3}{|c|}{ Initial } & \multicolumn{8}{|c|}{ Path [Unit: MPa] } \\
\hline & \multirow{2}{*}{$\rho_{\mathrm{d}}[\mathrm{t} / \mathrm{m} 3]$} & \multirow{2}{*}{$e[-]$} & \multirow{2}{*}{$w[\%]$} & \multicolumn{2}{|c|}{ I } & \multicolumn{2}{|c|}{ II } & \multicolumn{2}{|c|}{ III } & \multicolumn{2}{|c|}{ IV } \\
\hline & & & & $\sigma_{\mathrm{v}}$ & $s$ & $\sigma_{\mathrm{v}}$ & $S$ & $\sigma_{\mathrm{v}}$ & $S$ & $\sigma_{\mathrm{v}}$ & $S$ \\
\hline $\mathrm{S} 1$ & 1.72 & 0.57 & 13.0 & 0.1 & 138 & 0.1 & 550 & 5.1 & 460 & 5.1 & 0 \\
\hline $\mathrm{S} 2$ & 1.68 & 0.60 & 13.7 & 0.1 & 126 & - & - & 9.1 & 127 & 9.1 & 0 \\
\hline S3 & 1.69 & 0.60 & 14.2 & 0.1 & 121 & 0.1 & 14 & 9.0 & 14 & 9.0 & 0 \\
\hline S4 & 1.71 & 0.58 & 12.9 & 0.1 & 119 & 0.1 & 3.7 & 8.4 & 4.1 & 8.4 & 0 \\
\hline S5 & 1.72 & 0.57 & 13.2 & 0.1 & 138 & 0.1 & 520 & 0.1 & 0 & 5.0 & 0 \\
\hline
\end{tabular}



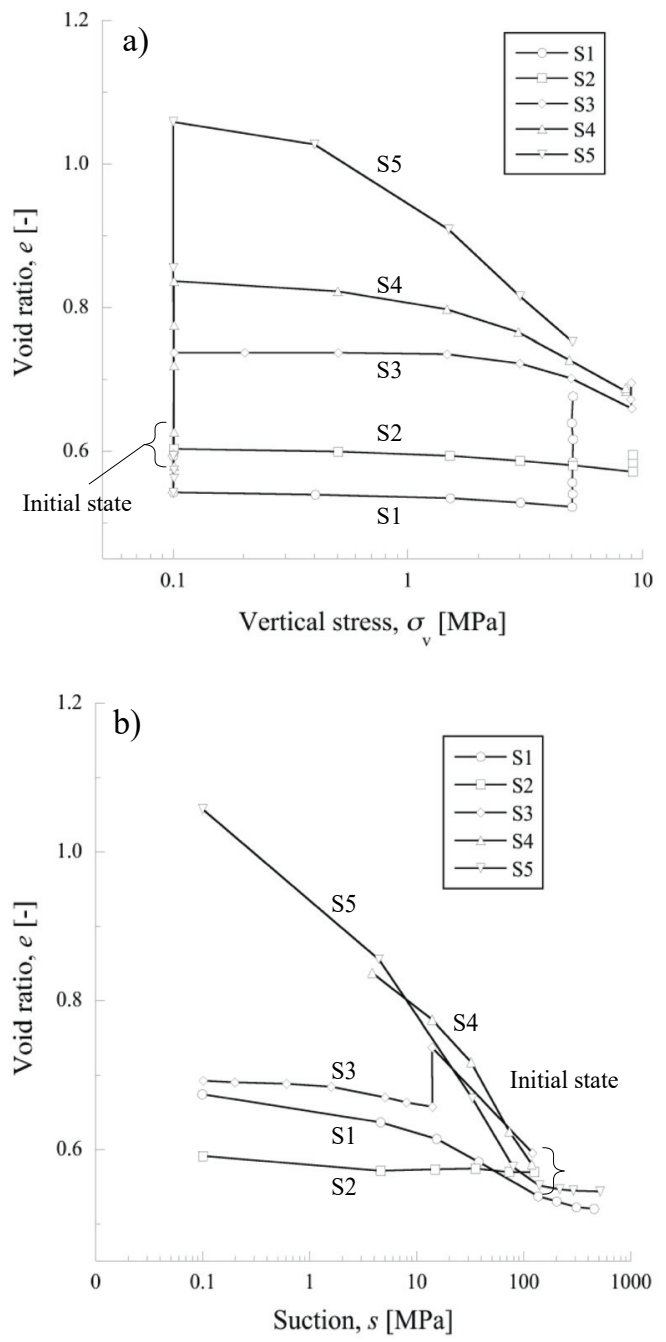

Fig. 6. Observed results of the oedometer tests with suction change on FEBEX bentonite (after Lloret, 2003 [2])

repulsion force changes according to the degree of saturation of soil skeleton. It was shown from the simulation of the suction-controlled oedometer test on the heavily compacted bentonite that the proposed model can suitably describe the mechanical behaviors of unsaturated expansive soil and hydraulic large swelling, which is the most typical characteristic of expansive soil. Such swelling behavior was described as a result of the combination of the interlaminar swelling, mechanical swelling and hydraulic collapse in the soil skeleton in the proposed model.

I would like to thank Kajima Corporation for partly supporting this research and Dr. S. Ohno for having a valuable discussion.

\section{References}

1. H. Kyokawa, S. Ohono and I. Kobayashi, A method for extending a general constitutive model to consider the electro - chemo - mechanical phenomena of
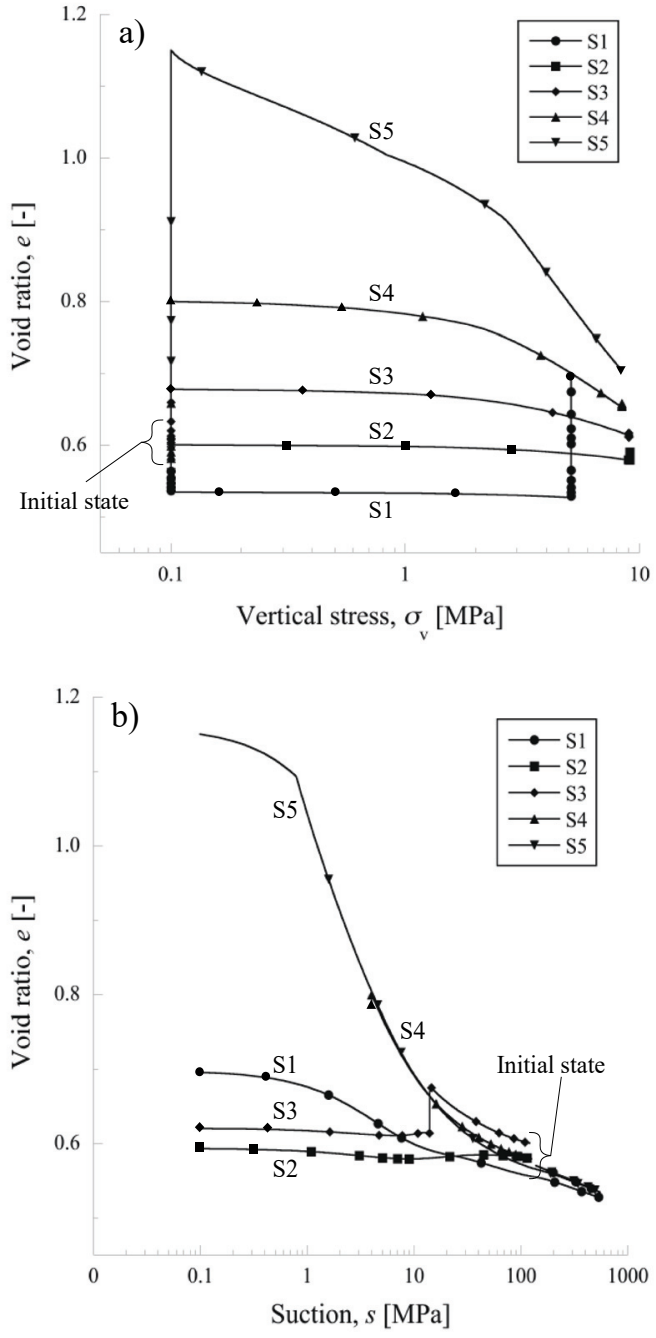

Fig. 7. Computed results of the proposed model

mineral crystals in expansive soils, Int. J. Numer. Anal. Met., 1-23 (2020)

2. A. Lloret, M.V. Villar, M. Sànchez, A. Gens, X. Pintado and E. E. Alonso, Mechanical behaviour of heavily compacted bentonite under high suction changes, Géotech., 53, 27-40 (2003)

3. D. Mašín, Double structure hydromechanical coupling formalism and a model for unsaturated expansive clays, Eng. Geol., 165, 73-88 (2013)

4. T.L.T. Zhan and W.W. Ng, Shear strength characteristics of an unsaturated expansive clay, Can. Geotech. J., 43, 751-763 (2006)

5. E. Romero, A microstructural insight into compacted clayey soils and their hydraulic properties, Eng. Geol., 165, 3-19 (2013)

6. M. Kikumoto, H. Kyokawa, T. Nakai and H.M. Shahin, A simple elasto-plastic model for unsaturated soils and interpretations of collapse and compaction behaviours, Proc. 5th International Conf. on Unsaturated Soils (UNSAT 2010), 849-855 (2010) 
7. E.E. Alonso, J.-M. Pereira, J. Vaunat and S. Olivella, A microstructurally based effective stress for unsaturated soils, Géotech., 60, 913-925 (2010)

8. D. Mašín and H. Khalili, Swelling phenomena and effective stress in compacted expansive clays, Can. Geotech. J., 53, 134-147 (2016)

9. T. Nakai and M. Hinokio, A simple elastoplastic model for normally and over consolidated soils with unified material parameters, S\&F, 44, 53-70 (2004)

10. R.N. Yong, Soil suction and soil-water potentials in swelling clays in engineered clay barriers, Eng. Geol., 54, 3-13 (1999)

11. H. Komine and N. Ogata, Prediction for swelling characteristics of compacted bentonite, Can. Geotech. J., 33, 11-22 (1996)

12. H.B.G. Casimir and D. Polder, The influence of retardation on the London-van der Waals forces, Physical Reviews, 73, 360-372 (1948)

13. S. Afzal, W.J. Tesler, S.K. Blessing, J.M. Collins, and L.J. Lis, Hydration force between phosphatidylcholine surfaces in aqueous electrolyte solutions, J. Col. \& Inter. Sci., 97, 303-307 (1983)

14. M.T., van Genuchten, A closed form equation for predicting the hydraulic conductivity of unsaturated soil, Soil Sci. Society of America J., 44, 892-898 (1980)

15. A. Seiphoori, A. Ferrari and L. Laloui, Water retention behaviour and microstructural evolution of MX-80 bentonite during wetting and drying cycles, Géotech., 64, 721-734 (2014)

16. V. Merchán, J. Vaunat, E. Romero and T. Meca, Experimental study of the influence of suction on the residual friction angle of clays, Proc. 1st European Conference on Unsaturated Soils, 423-428 (2008) 